\title{
ASSOCIATION BETWEEN SMOKING AND PERIODONTAL DISEASE: A REVIEW OF THE LITERATURE
}

Ramli J., Taiyeb Ali T.B.Association between smoking and periodontal disease. Annal Dent Univ Malaya 1999; 6: 21 26.

\section{ABSTRACT}

The role of smoking as a contributory factor in the progression of the periodontal disease process has long been suspected and recently a large number of studies have been published in the dental literature regarding this possible role. Much of the literature has also indicated that smokers affected with periodontitis respond less favorably to periodontal treatment be it non-surgical, surgical and regenerative. This paper will review the current literature regarding the effects of smoking on various aspects of the periodontal disease process and present an explanation for the possible association between smoking and the progression of periodontitis.

Keywords: smoking, periodontal disease

\section{INTRODUCTION}

For the last few decades, dentists and dental researches have become more aware of the critical role of smoking on the incidence and severity of periodontal disease(1), and smoking is now considered a risk factor in periodontal disease. There is a long history of association between tobacco smoking and periodontal disease. In 1983, Ismail et al. (2) analyzed smoking and periodontal disease and found that after adjusting for potential confounding variables such as age, oral hygiene, gender and socioeconomic status, smoking remained a major risk indicator for periodontal diseases. Locker and Leake(3) found that among Canadians, smoking was one of the most consistent predictors of periodontal disease experience. In a study of more than 1,400 subjects, aged 25 to 74 from Erie Country, New York, it was found that smokers had an increased relative risk for periodontitis ranging from 2.05 to 7.28 for light and heavy smokers, respectively $(4,5)$. According to Bergstrom \& Preber (6), tobacco smoking has substantial influence on periodontal health and disease and is associated with an increased disease rate in terms of periodontal bone loss, periodontal attachment loss as well as periodontal pocket formation. It is well established that tobacco use in general and the widespread habit of cigarette smoking in particular, is a major risk factor in the incidence and severity of several forms of periodontal disease. These forms include acute necrotizing ulcerative gingivitis, chronic adult periodontitis and refractory periodontitis.

\section{Smoking and Plaque}

Smoking and Plaque Accumulation

Preber et al. (7,8), Feldman et al. (9), and Ismail et al. (2) observed smokers to have decreased levels of oral hygiene when compared to non-smokers. The toothbrushing efficiency of smokers was much less (10) and the calcium concentration in the dental plaque of smokers was found to

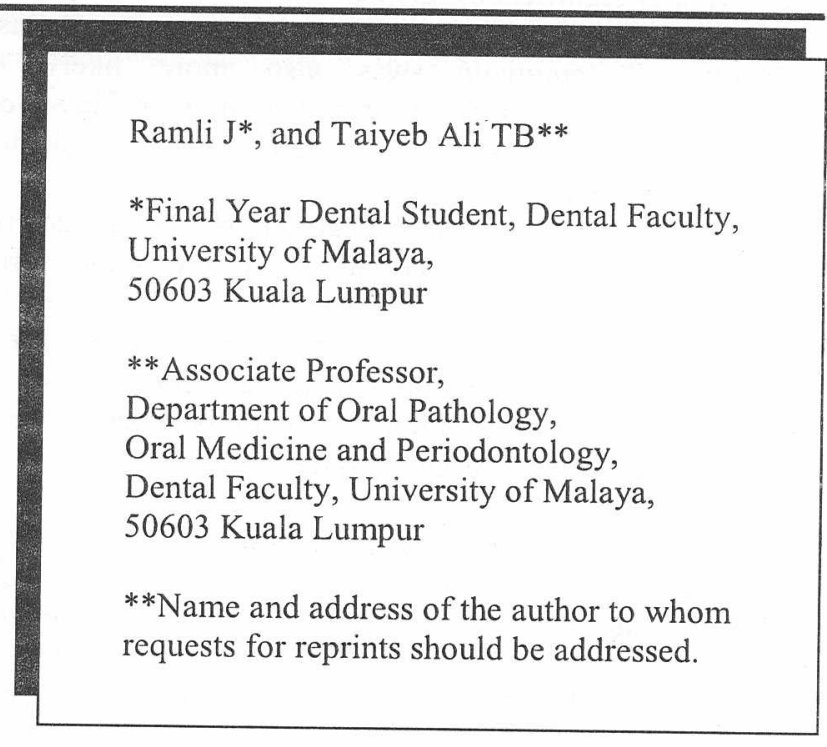

be significantly higher than in non-smokers (11), suggesting an influence on the rate of calculus formation and further deterioration of oral hygiene

Results of studies investigating the relationship between smoking and plaque formation have however been contradictory. Preber et al. in 1980(7) reported higher plaque index scores in smokers than non-smokers. Males had significantly more plaque than females and in both sexes, smokers had almost twice the percentage of marginal line with adherent plaque as non-smokers. It has been suggested that plaque may possibly be more adherent to the tooth and less readily removed from the teeth of smokers due to the deposition of tars contained in the tobacco smoke (12).

By contrast, others found that both cigarette and pipe/cigar smokers accumulated less plaque than nonsmokers (8). No significant differences in plaque formation were found between non-smokers and smokers, smoking 10 to 40 cigarettes per day (13). Likewise further studies also failed to find any correlation between smoking and plaque formation $(14,15,16)$.

\section{Smoking and Plaque Microflora}

Cigarette smoking could cause a lowering of the oxidation-reduction potential (Eh), and this could cause an increase in anaerobic plaque bacteria. Eh values in the gingiva was shown to drop significantly after smoking one cigarette (17). Nisseria (Gram-negative aerobe) were found to be less numerous in the plaque, tongue and palate of five young men who smoked more than 20 cigarettes a day when compared to four who did not smoke (18) and there were more Veillonella and Bacteroides isolated from the tongues of smokers than non-smokers. They stated that the changes could have resulted from more anaerobic conditions prevailing in smokers or to antibacterial properties of the tobacco smoke. Tobacco smoke contains phenols and cyanides, which can account for antibacterial 
and toxic properties.

Smokers harboured significantly higher levels and were at significantly greater risk of infection with $B$. forsythus than non-smokers (19). Adjusting for disease severity, $P$. gingivalis was also more likely to subgingivally infect smokers than non-smokers. However, there was not a significantly higher relative risk for infection with this bacterium.

The in vitro effect of cigarette smoke on bacteria was also examined $(20,21)$ and it was found that three species of Gram-negative bacteria, Branhamella catarrhalis, Neisseria perflava and Neisseria sicca were more susceptible to cigarette smoke than three species of Gram positive bacteria Streptococcus mitis, Streptococcus salivarius and Streptococcus sangius.

\section{Effects of Smoking on Exocrine Glands}

A marked increase in parotid flow rate was reported following smoking a cigarette (22). Regular smoking showed no significant alteration in salivary secretion. However in the novice smokers, smoking markedly increases the flow rate of saliva (23).

Reports that calculus formation is more abundant in smokers may be due to the increased salivary flow rates. There is an increased calcium concentration in fresh saliva in smokers following smoking (24). Nicotine affects the exocrine glands by an initial increase in salivary and bronchial secretions that are followed by inhibition of the secretions.

The initial salivation produced by smoking is probably caused by smoke irritation and the acidity of cigarette smoke. The alteration of the salivary flow or microflora may be responsible for the increased calculus prevalent in smokers (25).

\section{Effects of Vascular Changes Following Smoking}

Nicotine from cigarette stimulates the sympathetic ganglia and adrenal medulla to produce neurotransmitters including epinephrine and catecholamine. These affect the alpha-receptors on blood vessels which in turn causes vasoconstriction (26). The vasoconstriction of peripheral blood vessels caused by smoking can also effect the periodontal tissue (27) as smokers have less overt signs of gingivitis than non-smokers and clinical signs of gingival inflammation such as redness, bleeding and exudation are not as evident in smokers. The vasoconstrictive actions of nicotine may be responsible for the decreased gingival blood flow.

\section{Effects of Smoking on Polymorphonuclear Leukocytes}

The polymorphonuclear leukocytes (PMNs) are the first line of defence in an inflammmatory response. It was discovered that a single cigarette provided enough toxic material to completely inhibit the function of oral salivary PMNs in-situ (28).

Kenney et al. in $1977(29)$ reported that the phagocytic capability of the PMNs from smokers was less than that from non-smokers and the impairment of PMNs function could be responsible for decreased defence of the gingiva against bacterial attack.
It was also reported by Kraal et al.(30) that cigarette induced slower rate of PMNs migration so more plaque could accumulate. Decreased effectiveness of PMNs may result in the degranulation of these cells and the release of more lysosomal enzymes, which would contribute to the severity of periodontal inflammation.

Smokers have higher blood PMN counts than do non-smokers (31) and chemotaxis of PMNs from smokers was suppressed relative to non-smokers (32).

\section{Smoking and Antibody Response}

Nicotine and the water-soluble fraction from whole cigarette smoke can suppress in vitro secondary antibody response (33). Salivary immunoglobulin A has also been found to be significantly decreased in smokers as compared to non-smokers (34).

Continued exposure to cigarette smoking has been shown to affect both humoral and cellular immune responses. Initially (hours to days) there is an acute depression of the immune response followed by stimulation (weeks to months) and finally depression of the immune system sets in. This included a decreased response to antigens and reduced serum concentration of $\mathrm{IgG}, \operatorname{IgM}$ and $\operatorname{IgA}$. Also gingival fluid exudate is reduced in smokers with the consequence that the carriage of leukocytes and immunoglobulins is likely to be diminished (35).

It was also noted that $\operatorname{IgG}_{2}$ serum level as well as antibody levels against Actinobacillus actinomycetemcomitans, were significantly depressed in subjects with adult periodontitis who smoked (36).

\section{Effects of Smoking on Lymphocytes}

Nicotine is also believed to affect $\mathrm{T}$ lymphocytes by increasing the number, decreasing the proliferation, decreasing their response to antigen and also decreasing $\mathrm{T}$ helper cells and increasing $\mathrm{T}$ suppressor cells (35). Individuals with Igood' lifestyle habits had higher natural killer cell counts than those found in a group reporting poor lifestyles that included smoking, alcohol intake, sleep, exercise and nutrition (37). Genotoxic effects of smoking have been investigated and smoking significantly increased micronuclei in lymphocytes (38), especially in the suppressor/cytotoxic T8 cells (39).

\section{Smoking and Gingivitis}

Preber et al. $(7,8)$ found smokers to have a greater severity of gingival inflammation than non-smokers and it was coincident with decreased oral hygiene. By contrast, some studies $(40,9,14)$ found no difference in gingival inflammation between smokers and non-smokers.

Bergstrom et al. in 1983(41) have found less gingival bleeding in smokers than in non-smokers, a finding which Palmer(42) suggests could be due to vasoconstriction of gingival vessels, but may also be attributable to the heavier keratinization of the gingivae in smokers.

Bergstrom et al. (16) also found gingival inflammation to be actually less pronounced in smokers than non-smokers. The reason suggested was the gingival 
inflammatory response to accumulating plaque might be suppressed under the influence of smoking (reduced capacity to mount and maintain an effective defence reaction)

\section{Acute Necrotizing Ulcerative Gingivitis and Smoking}

Smoking has long been considered an etiologic factor in acute necrotizing ulcerative gingivitis (ANUG). Pindborg in a series of studies starting in 1947 to 1951 determined that tobacco smoking was a factor in ANUG and that with the increase in the use of tobacco there was an increase in frequency of ANUG. Additionaliy, he felt that the tar in the smoke exerted a direct irritating effect on the gingiva giving rise to gingivitis, and that nicotine could caused contraction of the capillaries, thus interfering with the nutrition of the gingiva which consequently became less resistant to infection.

Shields (43) reported on a group of 90 patient of whom 45 had ANUG. He concluded that both stress and smoking were important factors in the pathogenesis of ANUG. The study found that smoking activates release of epinephrine and promotes contraction of peripheral vessels, reducing blood flow to the gingiva. The lesion of ANUG is contained within avascular epithelial tissue entirely dependent upon diffusion from the connective tissue for its oxygen and nutrient supply. Severe reduction of blood flow induced by sepsis, stress and smoking may cause loss of vitality to the most vulnerable regions of the gingival epithelium leading to the onset of ANUG (44).

Another possible mechanism for the pathogenesis of ANUG is an increased catecholamine level in ANUG patients which in association with endotoxin within the tissue could potentiate a localized Schwartzman reaction leading to localized death of tissue and the genesis of ANUG (45).

Depression of the host's defense mechanism by reduced vascular flow or from stress-related increases in steroid hormones, could exert selective influences on the plaque bacteria allowing certain microorganisms to overgrow and others to invade the compromised tissues (46). Besides the fuso-spirochetal organisms that have been associated with ANUG, Bacteroides melaninogenicus ssp. intermedius and others, whose prominence in plaque may be dependent upon host-derived factors, have been implicated (47).

\section{Pocket Depth, Attachment Loss and Alveolar Bone} Loss in Smokers

Cigarette smokers had significantly greater probing depths and bone loss than non-smokers although no difference was found in relation to tooth mobility (9). Bergstrom et al. (48) found smokers not only to have significantly increased probing depths and alveolar bone loss, but also increased tooth mobility. They further concluded that smoking mainly exerts a systemic influence. It effects the periodontium primarily by interfering with the body response mechanisms rather than by adding to local destructive factors.

Besides the presence of nicotine in gingival crevicular fluid it has also been found on the root surfaces of periodontally diseased teeth in smokers. Here it acts to affect the fibroblast by increasing the production of collagen, but impairs its secretion (49). In the presence of nicotine, the cell structures of the fibroblasts changed and it was apparent that they were not firmly attached to the root surfaces $(50)$. It is possible that a similar disturbance in fibroblast attachment occurs in people who smoke making them more susceptible to periodontal damage.

\section{Smoking and Tooth Loss}

Substantial epidemiological data indicate that smokers have fewer teeth, higher prevalence of edentulism and greater incidence of tooth loss than non-smokers (51). It was found that the relative risk for tooth loss is enhanced among young smokers, particularly males who smoke. Cigarette smokers with poor oral hygiene are also at a much greater risk of losing their teeth than non-smokers (52).

\section{Refractory Periodontal Disease(RPD) and Smoking}

Smoking seem to be an important risk factor for RPD. McFarlane et al. (53) reported that even with high quality oral hygiene, a retrospective search for associated environmental variables showed that $90 \%$ (28 out of 31 ) of the refractory patients were smokers. These patients showed peripheral blood PMNs with an unforseen abnormality. Phagocytic function was depressed when compared to unaffected controls.

Magnusson et al. (54) also reported that 19 out of 21 of their refractory patients had a history of smoking.

\section{Smoking and Its Effects on Periodontal Healing}

\section{Healing Following Non-surgical Treatment}

Following non-surgical therapy including scaling, root planing and professional tooth cleaning, healing in terms of gingival bleeding reduction and pocket depth reduction was less favorable in smokers as compared to nonsmokers. The influence of smoking on the short-term outcome of non-surgical therapy clinically as well as microbiologically was evaluated (55). The clinical results showed a statistically significant reduction of pocket depth and number of diseased sites in both smokers and nonsmokers patients. However, the reductions were less pronounced among smokers. Only $40 \%$ of diseased sites in smokers healed as compared to $57 \%$ in non-smokers, indicating a less favourable healing potential under the influence of smoking. This short-term finding supported earlier short-term results (56) and furthermore are in agreement with recent long-term results $(57,58)$ which suggest that tobacco smoking interferes with the healing process following non-surgical periodontal therapy.

The therapeutical efficacy with regard to supragingival plaque elimination was practically the same in both smoking groups, implying that the supragingival infection was reduced to the same low levels in both groups. With regards to the subgingival plaque microbiota, $A$. actinomycetemcomitans and $P$. gingivalis were almost totally eradicated and $P$. intermedius was reduced to about $30 \%$ in both groups (55). A study by Grossi et al. in 1997 (59) showed that current smokers have less healing and reduction in subgingival Bacteroids forsythus and Porphyromonas gingivalis after treatment compared to former and non-smokers, suggesting that smoking impair periodontal healing. 


\section{Healing Following Surgical Treatment}

A statistically significant difference was observed in the reduction of probing depth between smokers and nonsmokers at 12 month post-surgical follow-up after Widman flap surgery on 4 to $6 \mathrm{~mm}$ pockets (60). Smokers showed significantly less probing depth reduction than non-smokers, which persisted even after accounting for plaque. Smokers who received either modified Widman flap or mucoperiosteal flap surgery had significantly less reduction in pocket depth and gain in probing attachment levels during 6 years of maintenance therapy compared to non-smokers (57).

Cigarette smoking has also been associated with a reduced healing response after guided tissue regeneration(GTR) therapy in deep intrabony defects (61) and with an $80 \%$ failure rate in treatment of furcation defects (62).

\section{SUMMARY}

From the many epidemiological and clinical studies reviewed there is considerable evidence supporting a positive association between smoking and periodontal diseases. In conclusion, smoking can cause a number of changes within the periodontium which can predispose an individual to the progression of periodontal disease. Dentists have an important role in creating awareness among the public of the detrimental effects that smoking has on the periodontal and oral tissues and health in general. The smoking habits of all patients should be enquired during an oral examination and the patient should be strongly advised to stop smoking by pointing out the risks involved and the positive benefits gained from the breaking of this habit. It is essential then that the dentist is supportive in this role in an attempt to improve the oral and general health status of the individual.

\section{ACKNOWLEDGEMENTS}

This paper is part of a presentation at the First Dental Student Scientific Conference held in Kuala Lumpur on 19-20 November 1999. The authors would like to thank the Dean of the Dental Faculty, University of Malaya for approving the funds used for this project.

\section{REFERENCES}

1. Haber J, Wattles J, Crowley M, et al. Cigarette smoking: A major risk factor for periodontitis. J Dent Res 1991; 70: 590(Abstr: 2599).

2. Ismail AI, Burt BA, Eklund SA. Epidemiologic patterns of smoking and periodontal disease in the United States. J Am Dent Assoc.1983; 106: 617623.

3. Locker D, Leake JL. Risk indicators and risk markers for periodontal disease experience for older adults living independently in Ontario, Canada. J Dent Res 1993; 72: 9-17.

4. Grossi SG, Zambon JJ, Ho AW, Koch G, Dunford RG, Machtei EE, et al. Assessment of risk for periodontal disease :I. Risk indicators for attachment loss. J Periodontol 1994; 65(3): 260-267.

5. Grossi SG, Genco RJ, Machtei EE, et al. Assessment of risk for periodontal disease. II. Risk indicators for alveolar bone loss. J Periodontol 1995; 66(1): 23-29.
6. Bergstrom, J., and Preber, H. Tobacco use as a risk factor. J Periodontol 1994; 65: 545-550.

7. Preber, H., Kant, T. Effects of tobacco smoking on periodontal tissues of 15-year-old children. J Periodont.Res. 1973; 8: 278.

8. Preber, H., Kant, T., Bergstrom, J. Cigarette smoking, oral hygiene and periodontal health in Swedish army conscripts. J Clin .Periodontol 1980; 7: 106-113.

9. Feldman RS, Bravacos JS, Rose CL. Association between smoking different tobacco products and periodontal disease indexes. J Periodontol 1983; 54: 481-487.

10. MacGregor ID. Tooth brushing efficiency in smokers and non-smokers. J Clin.Periodontol 1984; 11: 313320.

11. MacGregor, I., Edgar, W., Greenwood, A. Effects of cigarette smoking on the rate of plaque formation. $J$ Clin.Periodontol 1985; 12: 35-41.

12. MacGregor, I.D.M. Survey of tooth brushing habits in smokers and nonsmokers. Clinical Preventive Dentisry $1985 ; 7(6): 27-29$.

13. Swenson, H. The effects of cigarette smoking on plaque formation. J Periodontol 1979; 50: 146-147.

14. Markkanen, H., Paunio, E. Cigarette smoking and periodontal health in Finnish adult population. J Dent.Res, 1984; 63: 578.

15. Danielson, B., Manji, F., Naqelkerke, N., Fejerskov, O., Baelum, V. Effect of cigarette smoking on the transitional dynamics in experimental gingivitis. $\mathrm{J}$ Clin.Periodontol 1990; 17: 159-164.

16. Bergtrom, J., Preber, H. The influence of cigarette smoking on the development of experimental gingivitis. J Periodont.Res.1986; 21: 668-676.

17. Kenney, E., Saxes, S., Bowles, R. The effects of cigarette smoking on anaerobiosis in the oral cavity. $\mathrm{J}$ Periodont.1975; 46: 82-85.

18. Colman.G., Beighton, D., Chalk, A.J, and Wake, S. Cigarette smoking and the microbial flora of the mouth.Aust Dent J, 1976; 21: 111-118.

19. Zambon J.J., Grossi, S.G., Machtei, E.E., Ho A, Dunford R, Genco, R.J.: Cigarette smoking increases the risk for subgingival infection with periodontal pathogents. J Periodontol 1996; 67 (Suppl.10): 10501054.

20. Bardell, D., and Smith, J.E.: An in vitro study of mixed populations of normal oropharyngeal bacteria to cigarette smoke. Microbios, 1979; 26: 159.

21. Bardell, D.: Viability of six species of normal oropharyngeal bacteria after exposure to cigarette smoke in vitro. Microbios, 1981; 32: 7.

22. Pangborn, R.M. and Sharon, I.M.. Visual deprivation and parotid response to cigarette smoking. Physiology and behaviour. 1971; 6: 559-561.

23. Parvinen, T. Stimulated salivary flow rate, $\mathrm{pH}$ and lactobacillus and yeast concentrations in non-smokers and smokers. Scandinavian Journal of Dental Research, 1984; 92: 315-318.

24. MacGregor, I.D.M and Edgar, W.M. Calcium and phosphate concentrations and precipitate formation in whole saliva from smokers and non-smokers. J Periodontol Res, 1984; 92: 315-318. 
25. Baab D, Oberg, PA. The effect of cigarette smoking on gingival blood flow in humans. J Clin. Periodontol.1987; 14: 418-424.

26. Goodman AG, Rall TW, Niles A, et al(eds). The Pharmacological Basis of Therapeutics, ed. 8, New York, Pergamon Press, 1990; pp 187-220.

27. Clark, N.G and Hirsch, R.S. Personalized risk factors for generalised periodontitis. J Clin. Periodontol, 1995; 22: 136-145.

28. Eichel, B., Sharik, H. Tobacco smoke toxicity: loss of human oral leukocyte function and fluid cell metabolism. Science, 1969; 166: 1424.

29. Kenney, E.B., Kraal, J.H., Saxe, S.R., Jones, J.. The effect of cigarette smoke on human oral polymorphonuclear leukocytes. J Periodont Res, 1977; 12: $227-234$

30. Kraal, J.H., Chancellor, M.B., Bridges, R.B., et al. Variations in the gingival polymorphonuclear leukocyte migration rate in dogs induced by chemotactic autologous serum and migration inhibitor from tobacco smoke. J Periodont Res, 1977; 12: 242 249.

31. Noble, R., Penny, B. Comparison of leukocyte count and function in smoking and non-smoking young men. Infect. Immun, 1975; 12: 550 .

32. Bridges, R. The effects of tobacco smoke on chemotaxis and glucose metabolism of polymorphonuclear leukocytes. Infect.Immun, 1977; 5: 115 .

33. Roszman, T.L, and Rogers, A.S. The immunosuppressive potential of products derived from cigarette smoke. Am Rev. Respir. Dis, 1973; 108: 1158.

34. Bennet K.R., Read, P.C. Salivary immunoglobulin A levels in normal subjets, tobacco smokers and patients with minor aphthous ulceration. J oral Surg, 1982; 53; 461-465

35. McGuire, J., McQuade, M., Van Dyke, T. Cotinine in saliva and gingival crevicular fluid of smokers with periodontal disease. J Periodontol.1989; 60: 176-181.

36. Quin, S.M., Zhang, J.B., Gunsolley, J.C., Schenkein, H.A., Tew, J.G. Smoking, periodontitis, serum IgG2 and anti-A.actinomycetemcomitans. J Dent.Res, 1995; 74:157(Abstr.1168).

37. Kusaka, Y., Kondou, H.and Morimoto, K. Healthy lifestyles are associated with higher natural killer cell activity. Preventive Medicine, 1993; 21: 602-615.

38. Xue, K., Wang, S., Ma, G., Zhou, P., Zhang, R., Xu, Z., Chen, W.and Wang, Y. Micronucleus formation in peripheral blood lymphocytes from smokers and the influence of alcohol and tea-drinking habits. International Journal of Cancer, 1992; 50: 702-705.

39. Larramendy, M.and Knuutila, S. Increased frequency of micronuclei in $\mathrm{B}$ and $\mathrm{T} 8$ lymphocytes from smokers. Mutation Research, 1991; 259: 189-195.

40. Bastian, R., Waite, I. Effects of tobacco smoking on plaque development and gingivitis. J Periodontol 1978; 49: 480-482.

41. Bergstrom, J and Floderus-Myrhed, B. Co-twin study of the relationship between smoking and some periodontal disease factors. Community Dentistry and Oral Epidemology. 1983; 11: 113-116.
42. Palmer, R.M. Tobacco smoking and oral health .Health Education Authority Occasional.1987 Paper no.6.

43. Shields, W.D.: Acute necrotizing ulcerative gingivitis. A study of some of the contributing factors and their validity in an army population. J Periodontol, 1977; 48: 346

44. Kardachi, B.J.R., and Clarke, N.G.: Aetiology of acute necrotizing ulcerative gingivitis: a hypothetical explanation. J Periodontol, 1974; 45: 830.

45. Shapiro, L., Cuevas, P., Stallard, R.E., and Ruben, M.P.: Absence of the localized Schwartzman reaction following 6-OH dopamine sympathectomy. J Periodont Res, 1974; 9: 207.

46. Clarke, N.G., Shephard, B.C., and Hirsch, R.S.: The effects of intraarterial epinephrine and nicotine on gingival circulation. Oral Surg, 1981; 52: 577

47. Loesche, W.J., Syed, S.A., Laughon, B.E., and Stoll.J.: The bacteriology of acute necrotizing ulcerative gingivitis. J Periodontol, 1982; 53: 223.

48. Bergstrom, J., Eliasson, S., and Preber, H. Cigarette smoking and periodontal bone loss. J Periodontol $.1991 ; 62: 242-246$.

49. Cuff, M., McQuade, M., Scheidt, M., Sutherland, D., Van Dyke, T.: The presence of nicotine on the root surfaces of periodontally diseased teeth in smokers. J Periodontol 1989; 60: 564-569.

50. Raulin, L., McPherson, J., McQuade, M., Hanson, B.: The effect of nicotine on the attachment of human fibroblasts to glass and human root surfaces in vitro. J Periodontol, 1988; 59: 318-325.

51. Ahquist M, Bengtsson C., Hollender L, Lapidus L, Osterberg T.: Smoking habits and tooth loss in Swedish women. Community Dent "Oral Epidemiol 1989; 17: 144-147.

52. Holm G.: Smoking as an additional risk for tooth loss. J Periodontol 1994; 65: 996-1001.

53. MacFarlane, G.D., Herzberg, M.C., Wolff, L.F., Hardie, N.A.: Refractory periodontitis associated with abnormal polymorphonuclear leukocyte phagocytosis and cigarette smoking. J Periodontol 1992; 63: 908913

54. Magnusson, I., Low, S.B., McArthur, W.P., Marks, R.G., Walker, C.B., Maruniak, J., et al.: Treatment of subjects with refractory periodontal disease. J Clin Periodontol 1994; 21: 628-637.

55. Preber, H., Linder, L., Bergstrom, J.: Periodontal healing and periopathogenic microflora in smokers and non- smokers. J Clin Periodontol, 1995; 22: 946952.

56. Preber, H., Bergstrom, J.: Effects of non-surgical treatment on periodontal pockets in smokers and nonsmokers. J Clin Periodontol 1985; 13: 319-323.

57. Kaldahl, W.B., Johnson, G.K., Patil, K.D., Kalkwarf,K.L.: Levels of cigarette consumption and responses to periodontal therapy. J Periodontol 1996; 67: 675-681.

58. Ah M.K., Johnson, G.K., Kaldahl, W.B., Patil, K.D., Kalkwarf, K.L.: The effect of smoking on the response to periodontal therapy. J Clin Periodontol 1994; 21(2): 91-97. 
59. Grossi, S.G., Zambon, J., Machtei, E.E.: Effects of smoking and smoking cessation on healing after mechanical periodontal therapy. J American Dental Association 1997; 128: 599-607.

60. Preber $\mathrm{H}$, Bergstrom, J.: Effects of cigarette smoking on periodontal healing following surgical therapy. $J$ Clin Periodontol 1990; 17(5): 324-32
61. Tonetti, M., Pin-Prato, G. and Cortellini, P.: Effects of cigarette smoking on periodontal healing following GTR in infrabony defects. A preliminary retrospective study. J Clin Periodontol 1995; 22: 229-234.

62. Miller, P.D.Jr.: Root coverage with the free gingival graft:factors associated with incomplete coverage. J Periodontol 1987; 58(10): 674-681. 